\begin{tabular}{|c|c|c|c|c|c|}
\hline tapraid5/trp-trp/trp-trp/trp99918/trp0276d18z & xppws & $\mathrm{S}=1$ & \begin{tabular}{l|l}
$10 / 19 / 18$ & $6: 28$ \\
\end{tabular} & Art: 2018-1297 & \\
\hline$\Psi_{\text {PSYCHOLOGICAL HYPNOSIS }} 30$ & & & \multicolumn{3}{|c|}{$\begin{array}{l}\text { Psychology of Consciousness: } \\
\text { Theory, Research, and Practice }\end{array}$} \\
\hline
\end{tabular}

\title{
The Phenomenology of REM-Sleep Dreaming: The Contributions of Personal and Perspectival Ownership, Subjective Temporality, and Episodic Memory
}

AQ: au

AQ: 1

\author{
Stan B. Klein \\ University of California, Santa Barbara
}

\begin{abstract}
Although the dream narrative, of (bio)logical necessity, originates with the dreamer, he or she typically is not aware of this. For the dreamer, the dream world is the real world. In this article, I argue that this nightly misattribution is best explained in terms of the concept of mental ownership (e.g., Albahari, 2006; Klein, 2015a; Lane, 2012). Specifically, the exogenous nature of the dream narrative is the result of an individual assuming perspectival, but not personal, ownership of the content she or he authored (i.e., "The content in my head is not mine. Therefore it must be peripherally perceived"). Situating explanation within a theoretical space designed to address questions pertaining to the experienced origins of conscious content has a number of salutary consequences. For example, it promotes predictive fecundity by bringing to light empirical generalizations whose presence otherwise might have gone unnoticed (e.g., the severely limited role of mental time travel within the dream narrative).
\end{abstract}

Keywords: dreams, personal ownership, subjective temporality, episodic memory

During the first years of the new millennium, I examined a patient with a very unusual impairment of memory. Despite suffering severe head injury, R. B. was able to recall events from his past that were rich in detail and independently verifiable (Klein \& Nichols, 2012). However, although he maintained perspectival ownership of retrieved content-that is, he knew it was "in my head" - he did not feel it personally owned. That is, he did not experience the content as "my memory." (The difference between personal and perspectival ownership is critically important in what follows. It is also subtle and thus liable to misunderstanding and confusion. distinction clear.)

I thank Carl Craver, Chris McFerron, and Jude Bijou for their help and encouragement. I particularly want to acknowledge Steve Lynn for his excellent advice and generous support.

Correspondence concerning this article should be addressed to Stan B. Klein, Department of Psychological and Brain Sciences, 551 Ucen Road, University of California, Santa Barbara, Santa Barbara, CA 93106. E-mail: klein@psych.ucsb.edu

For instance, asked to remember a time spent with friends, R. B. produced a thorough account of a social event from his college years. But, he lamented.

\footnotetext{
My memories [R. B.'s emphasis] do not feel in any way like they're my memories. They feel like facts I know, like that Washington was the first president. I can infer that they're about me because I know what they're about. . . . It doesn't take much (inference). But even then, when I figure out a memory is about me it doesn't help me take ownership. It feels like third party . . . like it belongs to some else. (Klein, 2016a, p. 492; parenthetical remark added for clarity)
}

The tension between elements of R. B.'s subjectivity (i.e., despite knowing that he must be the author-after all, the content was in his head-he was unable to take possessory custody of that content) suggested a potentially important insight into the workings of the mind. What I had was a collection of facts documenting R. B.'s paradoxical phenomenology. What I needed was a way to transition from fact to explanation. This meant aligning those facts with a theoretical framework capable of fitting them together in a logically defensible way (e.g., Margenau, 1950; Nagel, 1961; Trusted, 1979). 
Table 1

Notes on Personal and Perspectival Ownership

By personal ownership, I mean that the content presented to consciousness is experienced as originating exclusively within the person (i.e., it is "mine"). It is felt as part of one's sense of self (e.g., Klein, 2014a). In contrast, content delivered to consciousness via the senses is treated as external to the self (i.e., other). Such content has perspectival but not personal ownership.

\section{Personal Ownership}

Appropriation of content to the self is noninferential and prereflective. It is directly given to consciousness as "mine" (e.g., Klein, 2014a, 2015a; Lane, 2012; Zahavi, 2005, 2011). In James's (1890) colorful terms, personal ownership entails the feeling that one's subjective experiences are imbued with a sense of warmth and intimacy.

Personal ownership is related to, but not identical with, personal retrieval. Though they typically co-occur, on very rare occasions a person can believe that s/he retrieved content, yet still feel the content is not personally owned. Consider the case of patient R.B. Although R. B. believed he was responsible for bringing Content X into consciousness (as thought, image, etc.), he did not feel that $\mathrm{X}$ originated in his personal past. Absent a sense of personal ownership, R. B. treated the content in consciousness "other;" that is, he took it to be a first-person apprehension of external reality (i.e., "The memories I retrieved are not my memories;" for discussion, see Klein, 2014a, 2016a; Klein \& Nichols, 2012; Zahavi, 2011).

Given the automatic and flawless manner in which the relation between the content and personal ownership typically unfolds, we usually are unaware that there is a relation being forged. However, in certain clinical conditions the content presented to consciousness, despite its endogenous origins, lacks a sense of being personally owned. Under these (very unusual) circumstances, the normally invisible relation between content and personal ownership is made apparent by its absence. The afflicted individual may discover (e.g., via inference) that she or he authored the content, but this knowledge does not confer a directly given sense of personal ownership (e.g., Klein, 2013a, 2015a, 2015b, 2016a). Absent the ability to take possessory custody of content normally associated with self (e.g., my thoughts, my bodily appendages), subjective awareness is accompanied by a bewildering feeling of disconnectedness-i.e., what should be "self" is experienced as "non-self" (i.e., as other; e.g., Earle, 1972; Klein, 2014a; Klein \& Nichols, 2012; Lane, 2012; Zahavi, 2005).

2. Perspectival Ownership

Perspectival ownership is the experience that content in consciousness exists exclusively in "me" (specifically, "in my head"). It consists in the feeling that my conscious content appears in a manner different from that in which conscious content appears to anyone else. Unlike personal ownership, perspectival ownership can be associated with endogenously generated or externally perceived content.

While all personally owned content is, of logical necessity, also perspectivally owned, perspectival ownership does not guarantee that an intentional object will be felt as personally owned (Patient R. B. is a case in point). Readers may find this hard to accept. The relation between personally retrieved conscious content and personal ownership is a default mode (e.g., Klein, 2015a; Lane, 2012). To appreciate the experience of perspectival ownership in the absence of personal ownership requires we actually undergo that experience (e.g., Nagel, 1974). I hope the reader will never be in that position.

3. The Contingent Nature of Personal and Perspectival Ownership

The connection between content in consciousness and types of ownership is not intrinsic ( $\mathrm{X}$ is an intrinsic property of Y if Y's having the Property X does not consist in Y also having a relation, Z, to something else). Rather it is one of contingency (i.e., it is annexed to, rather than a basic constituent, of the intentional object; Klein, 2013a, 2014a, 2014c, 2014d, 2015a; Lane, 2012). Patient R. B., for example, lost and subsequently regained personal ownership of the content retrieved into consciousness (e.g., Klein \& Nichols, 2012).

When the sense of personal or perspectival ownership is rendered dysfunctional by a clinical disorder (e.g., somatoparaphrenia, depersonalization, pain asymbolia), the mechanisms that enable a person to take noninferential possessory custody of content that, of ontological necessity, is authored by the person, no longer operate (though $\mathrm{s} /$ he does not know it). Under these circumstances, the consciousness content is treated as external in origin.

On occasion, a person suffering from a clinically mediated loss of personal ownership may transition from a directly given feeling to a sense of personal ownership based on logical inference (e.g., because $\mathrm{X}$ is in my head, it must be mine). However, although inference enables the patient to take custody of content in consciousness, the shift from "pre-reflective given" to "product of inference" imbues this acquired (i.e., nonautomatic) ownership with a upsetting feeling of experiential detachment (that is, "While I can infer X must be mine, it does not feel personally owned; e.g., Albahari, 2006; Klein, 2015a; Lane, 2012; Zahavi, 2005, 2011; Zahn, Talazko, \& Ebert, 2008).

4. Ownership, Self and Other

Personal ownership is the mental wedge that enables us to distinguish self from non-self (Klein, 2014a). What makes consciousness content "mine" is that I intuitively sense-without need for intuition, inference, or reflection-the content as originating within "me." Absent this, content is experienced as issuing from a reality that exists independently of the self (for discussions, see Albahari, 2006; Klein, 2013a, 2015a; Lane, 2012; Zahavi, 2011). 
Seeking direction, I conducted a search of the literature on "memory" and "loss of personal ownership." Unfortunately, little light was shed on R. B.'s discordant phenomenology. The only case bearing a resemblance was reported by Talland (1964). However, the paucity of detail he provided made any attempt at drawing parallels between cases ill-advised. Unable to find empirical or conceptual guidance, I set aside R. B.'s files and turned my attention to less perplexing issues.

But the mystery of R. B.'s anomalous subjectivity continued to haunt me. After a hiatus of nearly half a dozen years, I returned to the literature. This time, however, I broadened my search to include any neurocognitive pathology (not just one of memory) whose symptoms included an inability to take noninferential possessory custody of one's intentional objects. (I sometimes refer to "content in consciousness" as "intentional objects." Intentionality, in the literature on philosophy of mind, refers to the proposition that every consciousness state is about or directed at some object. Intentional object is the name given to content accorded conscious consideration; Brentano, 1995; Textor, 2013; Thomassoin, 2000).

Casting a larger net proved propitious, bringing in tow an assortment of (mostly esoteric) neurocognitive pathologies (e.g., anosagnosia, somatoparaphrenia, depersonalization, pain asymbolia) in which loss of personal ownership was a symptom (e.g., disavowing possession of one's bodily appendages, thought insertion, hallucinations; for reviews see Klein, 2015a; Lane, 2012; Stephens \& Graham, 2000). R. B.'s subjective disharmony could now be situated in a well-developed conceptual framework capable of introducing order and coherence to what appeared to be irreconcilable elements of his phenomenology (while beyond the scope of this paper, an account of the mental machinery responsible for R. B.'s fractured phenomenology can be found in Klein, 2015a). Fact had given way to explanation.

\section{AQ: 3 The Normalcy of Personal Ownership and Its Loss}

What I had taken to be a unique pathology of subjectivity thus proved more common than suspected: Examples could be found-provided loss of personal ownership was not limited to afflictions of memory. In another sense, however, the phenomenon remained elusive: When manifest, it appeared only as a symptom associated with a few comparatively uncommon neurocognitive disorders.

In this paper, I argue that loss of personal ownership of one's intentional objects is more than a symptomatic curiosity attending certain clinical conditions. Rather, it is an accompaniment of a perfectly normal nightly occurrence-the rapid-eye movement (REM)-sleep dream. Although a dream narrative is, of biological necessity, authored by the dreamer, he or she does not know this (unless the dream is lucid; e.g.,Voss, Schermelleh-Engel, Windt, Frenzl, \& Hobson, 2013). For the dreamer, the dream world is the real world (e.g., Foulkes, 1985; Hobson, 2009; McNamara, McLaren, \& Durso, 2007; Soper, Rosenthal, \& Milford, 1994; Tranquillo, 2014; Zadra \& Domhoff, 2016; Zippel, 2016). Considered from the perspective of mental ownership, dream phenomenology is a naturally recurring, nonpathological state in which an individual maintains perspectival, but not personal, ownership of content she or he authored (this also occurs during nonrapid-eye movement [NREM]sleep dreaming-e.g., Cavallero, Foulkes, Hollifield, \& Terry, 1990; MacDuffie \& Mashour, 2010; Wamsley, 2013. However, in this article I restrict discussion to dreams occurring during REM sleep).

\section{Contemporary Explanations for the Misattribution of the Origins of Dream Content}

The schism between the endogenous origins of dream content and its treatment as a series of perceptually given, often surreal, exogenous events has been recognized since antiquity (e.g., Foulkes, 1985). Most contemporary psychological accounts of dream-source misattribution explain the phenomenon in terms of degradation in the function of some psychological faculty (e.g., reasoning, remembering, self, consciousness).

Recounting all the explanations offered for dream-source misidentification would be prohibitive, but those currently receiving serious attention include (a) reduced capacity to evaluate, monitor, and reflect on content in consciousness (e.g., Darling, Hoffmann, Moffitt, \& 
Purcell, 1993; Hobson, 2009; Nir \& Tononi, 2010); (b) limited availability of memories that would provide a context within which to evaluate the bizarre content of the dream (e.g., Hobson \& Friston, 2012; Foulkes, 1985; MacDuffie \& Mashour, 2010; McNamara et al., 2007; Tranquillo, 2014); (c) impairment of mechanisms that would allow the dreamer to identify the hallucinatory quality of dream content (e.g., Hobson, 1999; Occhionero, Cicogna, Natale, Esposito, \& Bosinelli, 2005; Tranquillo, 2014; Zippel, 2016); (d) diminished capacity of the dreamer to engage in logical reasoning (e.g., Maquet et al., 2005); (e) regression to a rudimentary form of consciousness (i.e., protoconsciousness) that cannot support reflective thought (e.g., Hobson, 2009; Hobson, PaceSchott, \& Stickgold, 2000; Solms, 2013); and (f) restricted access to "mental activeness," a psychological trait that enables the dreamer to diagnose the compromised character of his or her phenomenology (e.g., O'Shaughnessy, 2000).

\section{Scientific Theory and Scientific Explanation in Broad Brush Strokes}

There are two outstanding characteristics of any scientific theory. First, the theory explains observed regularities by relating them to new entities which it educes as existent facts. Second it must be possible to deduce generalizations from the propositions of the theory which can be used to predict new observable facts. (Trusted, 1979, p. 73; emphasis in original)

Science can be viewed as the systematic exploration of relations between abstract theory and empirical evidence (e.g., Hempel, 1965; Klee, 1997; Margenau, 1950; Nagel, 1961; Trusted, 1979). Theory consists in a hypothetiAQ: 4 cal space occupied by constructs (i.e., explanatory variables not directly observable) and their interrelations. The empirical side consists in directly or indirectly observable data. The two are connected by rules that enable the formulation of generalizations to explain associations between abstract constructs and observable data (e.g., Klee, 1997; Klein, 2014b; Ladyman, 2002; Margenau, 1950; Trusted, 1979). To discourage the proliferation of ad hoc explanations, a scientific theory requires that these associations be supported by logical entailments between construct and empirical regularity. Because ad hoc explanations are explicitly tailored to a specific problem, such accounts lack gen- eralizability. Accordingly, the explanatory scope of an ad hoc account is restricted to the particular empirical regularity it was crafted to explain (e.g., Klein, 2014b, 2015b; Nagel, 1961; Trusted, 1979).

A theoretical structure consisting in abstract constructs linked to empirical regularities often goes by the name "nomological network" (e.g., Cronbach \& Meehl, 1955; Margenau, 1950; Torgerson, 1958). A nomological network is a theoretical space joining physical observations with a well-formulated and rationally integrated set of abstract constructs. Situating explanation within a nomological network not only enhances the epistemic warrant of our hypotheses, it also alerts us to relations between data and construct that might otherwise have gone undetected. It does by disclosing theory-driven implications different from those to which the explanation was originally fitted. This predictive ability is a critically important aspect of scientific theory and explanation (e.g., Klein, 2014b; Margenau, 1950; Newell, 1973; Trusted, 1979).

\section{Problems With Current Psychological Explanations of Dream Ontology}

Virtually all contemporary explanations of dream-source misattribution are riffs on a common theme: "Degradation of psychological faculty X" results in "failure to recognize the origins of dream content." Although it is presently impossible to empirically verify these proposals (rules wedding cause to effect are not currently available), this, in itself, is not cause for dismay: It simply underscores the nature of scientific explanation - that is, the need for further experimentation to clarify the relation between construct and data (e.g., Bartlett, 1932).

What is troubling is that these proposals are mostly grounded in ad hoc reasoning. Accordingly, variables recruited to explain dreamsource confusion (e.g., reflection, reasoning, remembering, evaluation) have few, if any, theoretically mandated causal connections with the phenomenon they are intended to explain. This, in turn, raises serious questions about their inferential warrant. Why, for instance, does degradation in the performance of Variable $\mathrm{X}$ (e.g., content evaluation) result in source missassignment as opposed to, say, a decrement in the clarity (imagistic, semantic, etc.) of content? 
Why does an unspecified amount of degradation in evaluative resources result in the complete failure to (correctly) experience dream content as endogenous in origin? How much judgmental degradation, or memory fragmentation, is required for the categorical shift from endogenous to exogenous source attribution found in the dream state? Lacking the requisite logical entailments, the case for specific cause-effect relations is more a matter of stipulation than principled deduction.

Another problem with these proposals is that their causal modus operandi-that is, source misattribution-is a consequence of impairment in the ability to evaluate dream-content origins. However, it is well-known that the manner in which content in consciousness assumes its phenomenological character (including its origins) is direct and prereflective: No evaluation, reflection, inference or other mental gymnastics are required (e.g., Albahari, 2006; Klein, 2014a; Klein, 2015a; Lane, 2012; Zahavi, 2005, 2011). Hence, judgment and evaluation play no part in ascertaining the source of an intentional object. ${ }^{1}$

In sum, the degradation theories of dream ontology are both conceptually and phenomenologically ill-suited to the job for which they were fashioned. Moreover, because these explanations are largely ad hoc, their explanatory reach is restricted to the particular phenomena they were designed to elucidate: Degradation accounts are likely to lead to epistemic dead ends.

\section{The Personal and Perspectival Ownership Explanation of Dream Ontology}

The problems attending degradation accounts of source attribution can be circumvented when explanation is located within a theoretical space specifically designed to address questions about the origin of content present in consciousness (e.g., Albahari, 2006; Klein, 2014a, 2015a; Lane, 2012; Stephens \& Graham, 2000; Zahavi, 2005). According to such accounts, misidentification of the source of the dream narrative is the direct consequence of the dreamer assuming perspectival ownership of the content he or she authored, but failing to take possessory custody. In consequence, the intentional object is treated as an external happening presenting to one's
Positioning explanation within a nomological network allows one to trace the logical entailments among constructs in the same network. This, in turn, fosters predictive fecundity: Discovering how constructs that figured in the initial explanatory effort are related to previously unexamined constructs occupying the same space promotes discovery of new empirical generalizations (e.g., Klein, 2014b; Newell, 1973; Torgerson, 1958; Trusted, 1979).

\section{Ownership as the Basis for Generating \\ Testable Predictions About the Role of Mental Time Travel in REM-Sleep Dreams: Logical Entailments}

The construct of Personal Ownership shares theoretical space with constructs that, on first view, appear to have no obvious relevance to questions pertaining to dream-source phenomenology. However, a careful examination of the interrelations between constructs offers insight into dream phenomenology that go well beyond the question of source identification. In what follows, I show how an analysis of the relation between Personal Ownership and Subjective Temporality can facilitate detection of new generalizations about the way in which we experience the dream narrative.

The form of Subjective Temporality directly relevant to present concerns is called mental time travel (for reviews see Klein, 2013a; Michaelian, 2016; Tulving, 2002; Suddendorf \& Corballis, 1997, 2007; Szpunar, 2010). Mental time travel refers to the possibility that a firstperson perspective can be subjectively located

\footnotetext{
${ }^{1}$ An exception to this "process blindness" occurs when the mechanisms that enable Personal Ownership are compromised by clinical disorders (e.g., depersonalization, somatoparaphrenia). Under these circumstances, the process that endows conscious content with a feeling of Personal Ownership is made conspicuous by its absence. Although some patients may attempt to make sense of their subjective dissonance (e.g., "The thoughts are in my head but are not mine") via inference (e.g., "Perhaps God is talking to me"), their explanations are accompanied by unsettling feelings of detachment (e.g., Albahari, 2006; Klein, 2012). In contrast, an analysis of content source is seldom, if ever, undertaken by the dreamer when dreaming (the exception being a person experiencing a lucid dream).

${ }^{2}$ The question of why the mechanisms enabling Personal Ownership are inactive during dreaming remains open. However, this explanatory gap in our understanding (i.e., the why question) is a constant among explanations currently in play.
} 
at time periods other than the present. It manifests when a person (a) remembers a past happening as if she or he were experiencing it again, or (b) imagines him or herself in a futureoriented scenario.

Drawing on the work of early 20th-century phenomenologists, Tulving (1985) proposed that the experience of mental time travel is a construct enabled by a mode of consciousness called Autonoesis: Autonoetic Consciousness ". . . mediates an individual's awareness of his or her existence and identity in subjective time extending from the personal past through the present to the personal future" (Tulving, 1985, p. 1). A person who possesses Autonoetic Consciousness "is capable of becoming aware of his or her own past as well as future; she or he is capable of mental time travel, roaming at will over what has happened as readily as over what might happen, independently of physical laws that govern the universe" (Tulving, 1985, p. 5).

The constructs of Personal Ownership and Autonoesis share an interesting, asymmetric, relation.

1. Autonoesis entails a sense of Personal Ownership (Autonoesis is Greek for selfknowing) because our capacity to subjectively experience ourselves at times other than the present requires that the remembered event or imagined scenario be "my" event or scenario (e.g., Klein, 2013b, 2016b; Klein, Loftus, \& Kihlstrom, 2002; Klein \& Steindam, 2016).

2. Absent Personal Ownership, a remembered event or imagined scenario would not be consciously regarded as "something that happened, or that might happen, to $m e$ " (i.e., it would not entail Autonoetic Consciousness). While I might, via inferential effort, situate the intentional object chronologically (e.g., I know that Hendrix died when I was in 12 th grade. That would be 1970), this would not be accompanied by a sense of reexperiencing the event in which that knowledge was acquired (e.g., Klein, 2013b, 2014a; Klein et al., 2002).

3. Personal Ownership does not require Autonoetic Consciousness. I can take possessory custody of an intentional object without having to locate that object temporally. For example, knowing that my name is Stan can be experienced as my knowledge, unaccompa- nied by any sense of temporal placement (beyond that of present experience; e.g., Klein, Robertson, \& Delton, 2011; Klein, 2016b: Klein \& Steindam, 2016c).

\section{Ownership as the Basis for Generating Testable Predictions About the Role of Mental Time Travel in REM-Sleep Dreams: Empirical Generalizations}

If misattribution of the origins of dream content is a result of loss of Personal Ownership, it follows that during a dream, the dreamer is denied access to Autonoetic Consciousness and therefore the ability to engage in mental time travel (see Point 2, above). He or she can know about, and respond to, current dream contingencies, but lacks the ability to survey the temporal landscape via acts of (a) reliving events that took place previously within the dream or (b) projecting him or herself into yet-to-be realized dream enactments. ${ }^{3}$ The dreamer is experientially tethered to the forward-moving "now" of the dream narrative. ${ }^{4,5}$

Although questions concerning subjective temporality are of interest to dream theorists (e.g., Crowther \& Soteriou, 2017; Grenier et al.,

AQ: 5

${ }^{3}$ This is not to say the dreamer lacks appreciation of things nonpresent. For example, anticipation, expectation, and goals all can exist in the moment (see Footnote 4). What it does mean is that the ability to mentally project oneself into the past or future is denied to the dreamer?

${ }^{4} \mathrm{My}$ use of the word the "now" is decidedly futureoriented. Analysis of the formal properties of the "present of objective time" reveals it to be instantaneous (e.g., Faye, 1989; McLure, 2005), becoming the next "present" essentially as soon as it makes an appearance (e.g., Husserl, 1964; James, 1890; Klein, 2013c). The present is a process consisting in an endless series of "nows" transitioning instantaneously to the "next" (as well as retreating into the past; e.g., Husserl, 1964). Thus, the subjective present necessarily is oriented toward and phenomenologically indistinguishable from what will be present (or, to a lesser degree, what has just been past). Even the well-worn idea of a "specious present" (e.g., Husserl, 1964; James, 1890) requires inclusion of protention-i.e., orientation toward the "next"-as an essential constituent of the present. In short, the moment of the present is, formally speaking, an abstract point in a temporal continuum constantly moving toward the "next" and away from the "previous."

5 Although I am not the first to propose that the dreamer's temporal experience is restricted to the present (e.g., Hobson, 1999; O'Shaughnessy, 2000), I am, to the best of my knowledge, the first to deduce this experiential myopia from examination of the logical entailments between constructs occupying a common theoretical space. 
2005; Hobson, 1999; MacDuffie \& Nashour, 2010), inquiries have focused primarily on comparing and contrasting temporality experienced while dreaming with temporal experience while awake. Examining the dreamer's capacity to wander the within-dream temporal landscape has, to my knowledge, not been afforded empirical consideration.

However, an approximation of the role of mental time travel in dream phenomenology can be procured from an investigation of the role of episodic memory in the dream narrative (e.g., Cavallero et al., 1990; Fosse, Fosse, Hobson, \& Stickgold, 2003; Malinowski \& Horton, 2014;
Schwartz, 2003). This is because the temporal commitments of mental time travel are isomorphic with those of episodic memory (e.g., Klein, 2013a, 2013b, 2014c, 2016b: Markowitsch, 2003; Michaelian, 2016; Suddendorf \& Corballis, 1997, 2007; Szpunar, 2010; Tulving, 1985, 1993, 2002, 2005; Wheeler, Stuss, \& Tulving, 1997; for discussion, see Table 2). Accordingly, an examination of episodic memory in the dream narrative can provide insight into the dreamer's ability to reexperience and preexperience aspects of the dream narrative.

Unfortunately, with one exception, examinations of the role of memory in dream phenom-

Table 2

The Evolution of Episodic Memory Criteria: A Synopsis

Episodic versus semantic memory

As initially conceptualized, episodic memory provided its owner with a record of the temporal, spatial and selfreferential features of the context in which remembered content was acquired (e.g., Tulving, 1972, 1983). In contrast, semantic memory was held to lack these contextual features: Its offerings are experienced as content devoid of knowledge concerning the circumstances in which it was attained.

Unfortunately, it subsequently was found that the core constituents of episodic memory (temporal, spatial and selfreferential) can also be on display during semantic memory experience (for reviews see Klein, 2013a; Kopelman, Wilson, \& Baddeley, 1989). Indeed, there are no principled reasons why the contextual features of these two systems should differ (for discussion, see Klein, 2013a, 2015b, 2017).

For instance, the assumption that episodic, rather than semantic, memory entails a self-referential component has given way to the well-recognized fact that knowledge in semantic memory also can be self-referential (for reviews, see Klein, 2010; Klein \& Lax, 2010; Renoult, Davidson, Palombo, Moscovitch, \& Levine, 2012). In addition, the content of semantic memory is capable of representing both spatial and temporal contextual information (e.g., "I know that John Lennon was born on October ninth, 1940 in Liverpool, UK, although I do not recollect the event in which that knowledge was acquired;" Klein, 2001; Kopelman et al., 1989; Tulving, Schacter, McLachlan, \& Moscovitch, 1988; for reviews, see Klein, 2004; Klein, 2010; Klein \& Lax, 2010; Martinelli, Sperduti, \& Piolino, 2013).

In short, a steady stream of untidy findings slowly chipped away at the traditional classification of episodic memory in terms of the criteria of time, space and self. Recognizing this, Tulving (1985) abandoned these criteria in favor of a distinction based on the different relations episodic and semantic memory had with subjective time. Episodic memory entails awareness that a current recollection refers directly to, and thus is experienced as, an event that transpired previously in one's life. In addition, episodic makes possible our ability to imagine ourselves in future-oriented scenarios (for recent reviews, see Klein, 2013a; Michaelian, Klein, \& Szpunar, 2016; Szpunar, 2010).

By contrast, the experience of content from semantic memory is occurrent-it is present to consciousness "now", either as thought or image. Though one can logically infer temporal facts about semantic memory (e.g., I know Jimi Hendrix played in New Haven. Because Hendrix died in 1970, the concert must have occurred around 1968; for discussion, see Klein, Loftus, \& Kihlstrom, 2002; Klein \& Steindam, 2016) feelings of personally re- or pre-living are not part of its experienced presentation.

The distinction between episodic and semantic memory is now recognized to involve differences in the subjective relations these systems have with the past and future. Episodic memory (a) enables one to re-experience events that transpired previously in his or her life, and (b) provides the evidential scaffolding on which future-oriented personal projection is crafted in imagination. Semantic memory experience, in contrast, is presented to consciousness only as occurrent. Adopting terminology proposed originally by Husserl (1964), Tulving labeled the types of temporal subjectivity accompanying the retrieval of episodic and semantic memory "autonoetic" and "noetic," respectively (e.g., Klein, 2014b; Tulving, 1985, 1993, 2002; Wheeler, Stuss, \& Tulving, 1997; Szpunar \& Tulving, 2011).

Tulving's reformulation of episodic memory in terms of temporal subjectivity has been widely adopted by memory researchers and has been shown to be a particularly fruitful way of generating testable hypotheses and evaluating models of memory (e.g., Perner \& Ruffman, 1994; Gardiner, 2001; Wheeler, 2005; Markowitsch \& Staniloiu, 2011; for reviews, see Michaelian et al., 2016; Wheeler et al., 1997). Unfortunately, with one exception (discussed below), dream researchers continue to use the outmoded, overly inclusive original criteria of time, space and self when examining the contributions of episodic memory to the dream phenomenology. 
enology (e.g., Baylor \& Cavallero, 2001; Cavallero et al., 1990; Fosse et al., 2003; Schwartz, 2003) have relied on an outdated, overly inclusive definition of the episodic memory (see Table 2). To date, the most comprehensive study of the role of episodic memory in dreaming found that less than $2 \%$ of 299 dream reports contained evidence of episodic recollection (Fosse et al., 2003). Thus, despite the adoption of overly liberal evidential criteria (i.e., one likely to include semantic as well as episodic memory; see Table 2), Fosse et al. (2003) found virtually no evidence that episodic memory features in dream phenomenology.

Fortunately, a recent study by Malinowski and Horton (2014) employed criteria that conformed closely to the current conceptualization of episodic memory (i.e., recollection characterized by Autonoetic Consciousness). Using the theoretically sanctioned definition, they found that one out of $186(0.5 \%)$ dream reports showed any evidence 6 of mental time travel (with episodic memory serving as the diagnostic proxy).

In sum, regardless of whether the empirical indices of episodic memory are too liberal, or are properly attuned to current theory (see Table 2 ), the role of mental time travel in dream phenomenology has been found to be essentially nonexistent (see Footnote 6). Consistent with predictions, the dreamer appears securely embedded within the forward-moving present moment of the dream narrative.

\section{Conclusion}

Wittgenstein (1997) astutely observed that we do not always need to look for explanations hiding beneath the surface, hidden from view. Often "the answer lies open to view and becomes surveyable by a rearrangement" (p. 92).

This is a particularly apt portrayal of our exploration into the cause of the discordant aspects of dream phenomenology. The best fitting explanation was the one grounded in a welldeveloped theory specifically tailored to questions of personal and perspectival ownership. Our inability to see an explanation "hiding in plain sight" was largely a consequence of the automatic and flawless manner in which the process of taking ownership of conscious content normally transpires: People tend not to consider, much less theorize about, processes whose existence they do not suspect. However, once it is appreciated that ownership of conscious content is a matter of contingency rather than necessity, its relevance to dream phenomenology becomes unmistakable.

An ownership account of dream-source misattribution has a number of salutary features. First, rather than ground explanation in appeal to the disruption of mechanisms that bear a tenuous relation to the phenomenon under investigation, an ownership account situates explanation within a theoretical space specifically tasked with finding answers to questions pertaining to the experienced origins of content in consciousness.

Second, an ownership account sees content misattribution as the result of a shift from one naturally occurring process (personal ownership) to another (perspectival ownership). There is no need to postulate empirically unsubstantiated entities (e.g., protoconsciousness $;^{7}$ mental activeness) buffeted about by theoretically unmotivated pathologies (e.g., degradation in evaluative competence as a function of REM-

\footnotetext{
${ }^{6}$ It is important to note that the sole episodic memory (i.e., "I dreamt about the argument. It was exactly the same as the real argument. I woke up not knowing if it was real;" Malinowski \& Horton, 2014, p. 445) was not autonoetic with respect to events that previously had taken place within the dream narrative: It was a dream reliving of an event that took place during waking life. Accordingly, the number of reported experiences of mental time travel occurring exclusively within the dream narrative was 0 out of 189 .

${ }^{7}$ Protoconsciousness (e.g., Hobson, 2009) is stipulated to be a primordial form of consciousness present prenatally and in infancy. Hobson has further assumed that protoconsciousness plays a foundational role in the emergence of the more fully-developed consciousness associated with later childhood and adulthood. With respect to dreaming, Hobson suggested that protoconsciousness is present throughout life and active particularly during REM-sleep dreaming. Unfortunately, protoconsciousness is a hypothesis awaiting empirical and conceptual evaluation. Empirically, assessment is, at best, challenging (e.g., Morin, 2006). Conceptually, serious scrutiny of the features ascribed to this embryonic consciousness has yet to be undertaken. As examples, what is the nature of the phenomenology associated with protoconscious? Are protoconscious experiences, in virtue of their primordial nature, less rich (less vibrant, less articulate, less explicit, etc.) than those associated with mature consciousness? Why does protoconsciousness remain present throughout the lifespan, especially during dreaming? These, and a host of questions concerning protoconsciousness, make clear that endowing the construct with causal potencies is premature.
} 
sleep dreaming; regression to a more primitive form of consciousness).

Finally, an ownership account promotes predictive fecundity by situating explanation within a nomological network. In so doing, it brings to light empirical generalizations whose presence might otherwise have gone unnoticed (e.g., the severely limited role of mental time travel within the dream narrative).

\section{References}

Albahari, M. (2006). Analytical Buddhism: The twotiered illusion of self. Houndsmills, UK: Palgrave Macmillan. http://dx.doi.org/10.1057/9780230 800540

Bartlett, F. C. (1932). Remembering: A study in experimental and social psychology. Cambridge, UK: Cambridge University Press.

Baylor, G. W., \& Cavallero, C. (2001). Memory sources associated with REM and NREM dream reports throughout the night: A new look at the data. Sleep: Journal of Sleep Research \& Sleep Medicine, 24, 165-170.

Brentano, F. (1995). Descriptive psychology. London, UK: Routledge.

Cavallero, C., Foulkes, D., Hollifield, M., \& Terry, R. (1990). Memory sources of REM and NREM dreams. Sleep: Journal of Sleep Research \& Sleep Medicine, 13, 449-455.

Cronbach, L. J., \& Meehl, P. E. (1955). Construct validity in psychological tests. Psychological Bulletin, 52, 281-302. http://dx.doi.org/10.1037/ h0040957

Crowther, T., \& Soteriou, M. (2017). Time in the dream. In I. Phillips (Ed.), The Routledge handbook of philosophy and temporal experience (pp. 184-200). London, UK: Routledge.

Darling, M., Hoffmann, R., Moffitt, A., \& Purcell, S. (1993). The pattern of self-reflectiveness in dream reports. Dreaming, 3, 9-19. http://dx.doi.org/10 $.1037 / \mathrm{h} 0094368$

Earle, W. E. (1972). The autobiographical consciousness. Chicago, IL: Quadrangle Books.

Faye, J. (1989). The reality of the future. Odense, Denmark: Odense University Press.

Fosse, M. J., Fosse, R., Hobson, J. A., \& Stickgold, R. J. (2003). Dreaming and episodic memory: A functional dissociation? Journal of Cognitive Neuroscience, 15, 1-9. http://dx.doi.org/10.1162/ 089892903321107774

Foulkes, D. (1985). Dreaming: A cognitive-phenomenological analysis. Hillsdale, NJ: Erlbaum.

Gardiner, J. M. (2001). Episodic memory and autonoetic consciousness: A first-person approach. Philosophical Transactions of the Royal Society of
London: Series B. Biological Sciences, 356, 13511361. http://dx.doi.org/10.1098/rstb.2001.0955

Grenier, J., Cappeliez, P., St-Onge, M., Vachon, J., Vinette, S., Roussy, F., . . de Koninck, J. (2005). Temporal references in dreams and autobiographical memory. Memory \& Cognition, 33, 280-288. http://dx.doi.org/10.3758/BF03195317

Hempel, C. G. (1965). Aspects of scientific explanation. In C. G. Hempel (Ed.), Aspects of scientific explanation and other essays in the philosophy of science (pp. 331-496). New York, NY: Macmillan.

Hobson, J. A. (1999). Dreaming as delirium: How the brain goes out of its mind. Cambridge, MA: MIT Press.

Hobson, J. A. (2009). REM sleep and dreaming: Towards a theory of protoconsciousness. Nature Reviews Neuroscience, 10, 803-813. http://dx.doi .org/10.1038/nrn2716

Hobson, J. A., \& Friston, K. J. (2012). Waking and dreaming consciousness: Neurobiological and functional considerations. Progress in Neurobiology, 98, 82-98. http://dx.doi.org/10.1016/j.pneurobio.2012.05.003

Hobson, J. A., Pace-Schott, E. F., \& Stickgold, R. (2000). Dreaming and the brain: Toward a cognitive neuroscience of conscious states. Behavioral and Brain Sciences, 23, 793-842. http://dx.doi .org/10.1017/S0140525X00003976

Husserl, E. (1964). The phenomenology of internal time-consciousness. Bloomington, IN: Indiana University Press.

James, W. (1890). Principles of psychology (Vol. 1). New York, NY: Henry Holt.

Klee, R. (1997). Introduction to the philosophy of science: Cutting nature at its seams. New York, NY: Oxford University Press.

Klein, S. B. (2001). A self to remember: A cognitive neuropsychological perspective on how self creates memory and memory creates self. In C. Sedikides \& M. B. Brewer (Eds.), Individual self, relational self, and collective self (pp. 25-46). Philadelphia, PA: Psychology Press.

Klein, S. B. (2004). The cognitive neuroscience of knowing one's self. In M. A. Gazzaniga (Ed.), The cognitive neurosciences: III (pp. 1007-1089). Cambridge, MA: MIT Press.

Klein, S. B. (2010). The self: As a construct in psychology and neuropsychological evidence for its multiplicity. WIREs Cognitive Science, 1, 172183. http://dx.doi.org/10.1002/wcs.25

Klein, S. B. (2012). The self and its brain. Social Cognition, 30, 474-518. http://dx.doi.org/10.1521/ soco.2012.30.4.474

Klein, S. B. (2013a). The complex act of projecting oneself into the future. WIREs Cognitive Science, 4, 63-79. http://dx.doi.org/10.1002/wcs. 1210 
Klein, S. B. (2013b). Making the case that episodic recollection is attributable to operations occurring at retrieval rather than to content stored in a dedicated subsystem of long-term memory. Frontiers in Behavioral Neuroscience, 7, Article 3. http://dx .doi.org/10.3389/fnbeh.2013.00003

Klein, S. B. (2013c). The temporal orientation of memory: It's time for a change of direction. Journal of Research in Applied Memory and Cognition, 2, 222-234. http://dx.doi.org/10.1016/j.jarmac .2013.08.001

Klein, S. B. (2014a). The two selves: Their metaphysical commitments and functional independence. New York, NY: Oxford University Press.

Klein, S. B. (2014b). What can recent replication failures tell us about the theoretical commitments of psychology? Theory \& Psychology, 24, 326338. http://dx.doi.org/10.1177/0959354314529616

Klein, S. B. (2014c). Autonoesis and belief in a personal past: An evolutionary theory of episodic memory indices. Review of Philosophy and Psychology, 5, 427-447. http://dx.doi.org/10.1007/ s13164-014-0181-8

Klein, S. B. (2014d). Sameness and the self: Philosophical and psychological considerations. Frontiers in Psychology, 5, Article 29. http://dx.doi.org/ 10.3389/fpsyg.2014.00029

Klein, S. B. (2015a). The feeling of personal ownership of one's mental states: A conceptual argument and empirical evidence for an essential, but underappreciated, mechanism of mind. Psychology of Consciousness: Theory, Research, and Practice, 2, 355-376. http://dx.doi.org/10.1037/cns0000052

Klein, S. B. (2015b). What memory is. WIREs Cognitive Science, 6, 1-38. http://dx.doi.org/10.1002/ wcs. 1333

Klein, S. B. (2016a). Lost feeling of ownership of one's mental states: The importance of situating patient R. B.'s pathology in the context of contemporary theory and empiricism. Philosophical Psychology, 29, 490-493. http://dx.doi.org/10.1080/ 09515089.2015.1126815

Klein, S. B. (2016b). Autonoetic consciousness: Reconsidering the role of episodic memory in futureoriented self-projection. The Quarterly Journal of Experimental Psychology, 69, 381-401. http://dx .doi.org/10.1080/17470218.2015.1007150

Klein, S. B. (2018). Remembering with and without memory. Psychology of Consciousness: Theory, Research, and Practice, 5, 117-130. http://dx.doi .org/10.1037/cns0000142

Klein, S. B., \& Lax, M. L. (2010). The unanticipated resilience of trait self-knowledge in the face of neural damage. Memory, 18, 918-948. http://dx .doi.org/10.1080/09658211.2010.524651

Klein, S. B., Loftus, J., \& Kihlstrom, J. F. (2002). Memory and temporal experience: The effects of episodic memory loss on an amnesic patient's abil- ity to remember the past and imagine the future. Social Cognition, 20, 353-379. http://dx.doi.org/ 10.1521/soco.20.5.353.21125

Klein, S. B., \& Nichols, S. (2012). Memory and the sense of personal identity. Mind, 121, 677-702. http://dx.doi.org/10.1093/mind/fzs080

Klein, S. B., Robertson, T. E., \& Delton, A. W. (2011). The future-orientation of memory: Planning as a key component mediating the high levels of recall found with survival processing. Memory, 19, 121-139. http://dx.doi.org/10.1080/09658211 .2010 .537827

Klein, S. B., \& Steindam, C. (2016). The role of subjective temporality in future-oriented mental time travel. In K. Michaelian, S. B. Klein, \& K. Szpunar (Eds.), Seeing the future: Theoretical perspectives on future-oriented mental time travel (pp. 135-152). UK: Oxford University Press. http://dx.doi.org/10.1093/acprof:oso/ 9780190241537.003.0007

Kopelman, M. D., Wilson, B. A., \& Baddeley, A. D. (1989). The autobiographical memory interview: A new assessment of autobiographical and personal semantic memory in amnesic patients. Journal of Clinical and Experimental Neuropsychology, 11, 724-744. http://dx.doi.org/10.1080/ 01688638908400928

Ladyman, J. (2002). Understanding philosophy of science. New York, NY: Routledge. http://dx.doi .org/10.4324/9780203463680

Lane, T. (2012). Toward an explanatory framework for mental ownership. Phenomenology and the Cognitive Sciences, 11, 251-286. http://dx.doi.org/ 10.1007/s11097-012-9252-4

MacDuffie, K., \& Mashour, G. A. (2010). Dreams and the temporality of consciousness. The American Journal of Psychology, 123, 189-197. http:// dx.doi.org/10.5406/amerjpsyc.123.2.0189

Malinowski, J. E., \& Horton, C. L. (2014). Memory sources of dreams: The incorporation of autobiographical rather than episodic experiences. Journal of Sleep Research, 23, 441-447. http://dx.doi.org/ $10.1111 /$ jsr. 12134

Maquet, P., Ruby, P., Maudoux, A., Albouy, G., Sterpenich, V., Dang-Vu, T., . . . Laureys, S. (2005). Human cognition during REM sleep and the activity profile within frontal and parietal cortices: A reappraisal of functional neuroimaging data. Progress in Brain Research, 150, 219-227, 595. http://dx.doi.org/10.1016/S0079-6123(05) 50016-5

Margenau, H. (1950). The nature of physical reality. New York, NY: McGraw-Hill.

Markowitsch, H. J. (2003). Autonoetic consciousness. In T. Kircher \& A. David (Eds.), The self in neuroscience and psychiatry (pp. 180-196). Cambridge, UK: Cambridge University Press. http://dx .doi.org/10.1017/CBO9780511543708.010 
Markowitsch, H. J., \& Staniloiu, A. (2011). Memory, autonoetic consciousness, and the self. Consciousness and Cognition: An International Journal, 20, 16-39. http://dx.doi.org/10.1016/j.concog.2010.09 .005

Martinelli, P., Sperduti, M., \& Piolino, P. (2013). Neural substrates of the self-memory system: New insights from a meta-analysis. Human Brain Mapping, 34, 1515-1529. http://dx.doi.org/10.1002/ hbm. 22008

McLure, R. (2005). The philosophy of time: Time before times. New York, NY: Routledge.

McNamara, P., McLaren, D., \& Durso, K. (2007). Representation of the self in REM and NREM dreams. Dreaming, 17, 113-126. http://dx.doi.org/ 10.1037/1053-0797.17.2.113

Michaelian, K. (2016). Mental time travel: Episodic memory and our knowledge of the personal past. Cambridge, MA: MIT Press.

Michaelian, K., Klein, S. B., \& Szpunar, K. K. (2016). Seeing the future: Theoretical perspectives on future-oriented mental time travel. UK: Oxford University Press. http://dx.doi.org/10.1093/acprof: oso/9780190241537.001.0001

Morin, A. (2006). Levels of consciousness and selfawareness: A comparison and integration of various neurocognitive views. Consciousness and Cognition: An International Journal, 15, 358-371. http://dx.doi.org/10.1016/j.concog.2005.09.006

Nagel, E. (1961). The structure of science. New York, NY: Harcourt Brace.

Nagel, T. (1974). What is it like to be a bat? The Philosophical Review, 83, 435-450. http://dx.doi .org/10.2307/2183914

Newell, A. (1973). You can't play 20 questions with nature and win: Projective comments on the papers of this symposium. In W. G. Chase (Ed.), Visual information processing (pp. 283-308). San Francisco, CA: Academic Press. http://dx.doi.org/10 .1016/B978-0-12-170150-5.50012-3

Nir, Y., \& Tononi, G. (2010). Dreaming and the brain: From phenomenology to neurophysiology. Trends in Cognitive Sciences, 14, 88-100. http:// dx.doi.org/10.1016/j.tics.2009.12.001

Occhionero, M., Cicogna, P., Natale, V., Esposito, M. J., \& Bosinelli, M. (2005). Representation of self in SWS and REM dreams. Sleep and Hypnosis, 7, 77-83.

O'Shaughnessy, B. (2000). Consciousness and the world. UK: Oxford University Press.

Perner, J., \& Ruffman, T. (1995). Episodic memory and autonoetic consciousness: Developmental evidence and a theory of childhood amnesia. Journal of Experimental Child Psychology, 59, 516-548. http://dx.doi.org/10.1006/jecp.1995.1024

Renoult, L., Davidson, P. S. R., Palombo, D. J., Moscovitch, M., \& Levine, B. (2012). Personal semantics: At the crossroads of semantic and epi- sodic memory. Trends in Cognitive Sciences, 16, 550-558. http://dx.doi.org/10.1016/j.tics.2012.09 .003

Schwartz, S. (2003). Are life episodes replayed during dreaming? Trends in Cognitive Sciences, 7, 325-327. http://dx.doi.org/10.1016/S1364-66 13(03)00162-1

Solms, M. (2013). Freud's "primary process" versus Hobson's "protoconsciousness." Contemporary Psychoanalysis, 49, 201-208. http://dx.doi.org/10 $.1080 / 00107530.2013 .10746545$

Soper, B., Rosenthal, G. T., \& Milford, G. E. (1994). Gender differences in dream perspectives. Psychological Reports, 74, 311-314. http://dx.doi.org/10 .2466/pr0.1994.74.1.311

Stephens, G. L., \& Graham, G. (2000). When selfconsciousness breaks: Alien voices and inserted thoughts. Cambridge, MA: MIT Press.

Suddendorf, T., \& Corballis, M. C. (1997). Mental time travel and the evolution of the human mind. Genetic, Social, and General Psychology Monographs, 123, 133-167.

Suddendorf, T., \& Corballis, M. C. (2007). The evolution of foresight: What is mental time travel, and is it unique to humans? Behavioral and Brain Sciences, 30, 299-313. http://dx.doi.org/10.1017/ S0140525X07001975

Szpunar, K. K. (2010). Episodic future thought: An emerging concept. Perspectives on Psychological Science, 5, 142-162. http://dx.doi.org/10.1177/ 1745691610362350

Szpunar, K. K., \& Tulving, E. (2011). Varieties of future experience. In M. Bar (Ed.), Predictions and the brain: Using our past to generate a future (pp. 3-12). New York, NY: Oxford University Press. http://dx.doi.org/10.1093/acprof:oso/9780195 395518.003.0008

Talland, G. A. (1964). Self-reference: A neglected component in remembering. American Psychologist, 19, 351-353. http://dx.doi.org/10.1037/ h0039768

Textor, M. (2013). Brentano on the dual relation of the mental. Phenomenology and the cognitive sciences, 12, 465-483. http://dx.doi.org/10.1007/ s11097-012-9281-Z

Thomassoin, A. L. (2000). After Brentano: A onelevel theory of consciousness. European Journal of Philosophy, 8, 190-209. http://dx.doi.org/10 $.1111 / 1468-0378.00108$

Torgerson, W. S. (1958). Theory and method of scaling. New York, NY: Wiley.

Tranquillo, N. (Ed.). (2014). Dream consciousness: Allan Hobson's new approach to the brain and mind. New York, NY: Springer. http://dx.doi.org/ 10.1007/978-3-319-07296-8

Trusted, J. (1979). The logic of scientific inference. London, UK: Palgrave. http://dx.doi.org/10.1007/ 978-1-349-16154-6 
Tulving, E. (1972). Episodic and semantic memory. In E. Tulving \& W. Donaldson (Eds.), Organization of memory (pp. 381-403). New York, NY: Academic Press.

Tulving, E. (1983). Elements of episodic memory. New York, NY: Oxford University Press.

Tulving, E. (1985). Memory and consciousness. Canadian Psychology, 26, 1-12. http://dx.doi.org/10 .1037/h0080017

Tulving, E. (1993). What is episodic memory? Current Directions in Psychological Science, 2, 6770. http://dx.doi.org/10.1111/1467-8721.ep10 770899

Tulving, E. (2002). Episodic memory: From mind to brain. Annual Review of Psychology, 53, 1-25. http://dx.doi.org/10.1146/annurev.psych.53.10 0901.135114

Tulving, E. (2005). Episodic memory and autonoesis: Uniquely human? In H. S. Terrace \& J. Metcalfe (Eds.), The missing link in cognition: Origins of self-reflective consciousness (pp. 3-56). Oxford, UK: Oxford University Press. http://dx.doi.org/10 .1093/acprof:oso/9780195161564.003.0001

Tulving, E., Schacter, D. L., McLachlan, D. R., \& Moscovitch, M. (1988). Priming of semantic autobiographical knowledge: A case study of retrograde amnesia. Brain and Cognition, 8, 3-20. http://dx.doi.org/10.1016/0278-2626(88)90035-8

Voss, U., Schermelleh-Engel, K., Windt, J., Frenzel, C., \& Hobson, A. (2013). Measuring consciousness in dreams: The lucidity and consciousness in Dreams Scale. Consciousness and Cognition: An International Journal, 22, 8-21. http://dx.doi.org/ 10.1016/j.concog.2012.11.001

Wamsley, E. J. (2013). Dreaming, waking conscious experience, and the resting brain: Report of subjective experience as a tool in the cognitive neurosciences. Frontiers in Psychology, 4, Article 637. http://dx.doi.org/10.3389/fpsyg.2013.00637
Wheeler, M. A. (2005). Theories of memory and consciousness. E. Tulving \& F. I. M. Craik (Eds.), The Oxford handbook of memory (pp. 597-608). UK: Oxford University Press.

Wheeler, M. A., Stuss, D. T., \& Tulving, E. (1997). Toward a theory of episodic memory: The frontal lobes and autonoetic consciousness. Psychological Bulletin, 121, 331-354. http://dx.doi.org/10.1037/ 0033-2909.121.3.331

Wittgenstein, L. (1997). Philosophical investigations (2nd ed.). (G. E. M. Anscombe, Trans.). Oxford, UK: Blackwell.

Zadra, A., \& Domhoff, W. (2016). Dream content: Quantitative findings. In M. Kryger, N. Roth, \& W. C. Dement (Eds.), Principles and practice of sleep medicine (6th ed., pp. 585-594). Philadelphia, PA: W. B. Saunders.

Zahavi, D. (2005). Subjectivity of selfhood: Investigating the first-person perspective. Cambridge, MA: MIT Press.

Zahavi, D. (2011). The experiential self: Objections and clarifications. In M. Siderits, E. Thompson, \& D. Zahavi (Eds.), Self, no self: Perspectives from analytical phenomenological and Indian traditions (pp. 56-78). UK: Oxford University Press.

Zahn, R., Talazko, J., \& Ebert, D. (2008). Loss of the sense of self-ownership for perceptions of objects in a case of right inferior temporal, parietooccipital and precentral hypometabolism. Psychopathology, 41, 397-402. http://dx.doi.org/10.1159/ 000158228

Zippel, N. (2016). Dreaming consciousness: A contribution from phenomenology. Rivista Internazionale Di Filosofia E Psicologia, 7, 180-201.

Received August 3, 2018

Revision received September 17, 2018 Accepted September 17, 2018 


\section{AUTHOR QUERIES}

\section{AUTHOR PLEASE ANSWER ALL QUERIES}

AQau-Please confirm the given-names and surnames are identified properly by the colors. = Given-Name, $\mathbf{a}=$ Surname The colors are for proofing purposes only. The colors will not appear online or in print. AQ1-Author: Do you mean "salutary" here?

AQ3-Author: Per APA style, your first heading has been changed from Level 2 to Level 1. Subsequent headings are arranged accordingly.

AQ4-Author: Please confirm or correct the addition of "latent" here.

AQ5-Author: Grenier et al., 2003 is not listed in your references. Please list in the references or remove all citations to it from the text.

AQ6-Author: Foulkes, Hollifield, \& Terry, 1990 is not listed in your references. Please list in the references or remove all citations to it from the text.

AQ7-Author: Grenier, J., Cappeliez, P., St-Onge, M., Vachon, J., Vinette, S., Roussy, F., . . . de Koninck, J. (2005) is not cited in your text. Please cite in the text or remove from the references. 